\title{
PLATELET CONCENTRATES FOR PERIODONTAL REGENERATION
}

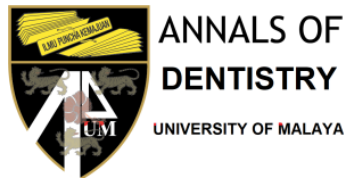

www.adum.edu.my

Ann Dent UM 2020, 27:55-65

Dol: 10.22452 /adum.vol27no9

\author{
Prabha Kadakampallil John ${ }^{1 *}$, Thomas George Valliaveettil ${ }^{1}$, Annie \\ Kitty George ${ }^{1}$, Alenya Mary Pyas ${ }^{1}$
}

\section{KEYWORDS}

Platelet concentrates, platelet rich plasma, platelet rich fibrin, injectable platelet-rich fibrin, titanium platelet-rich fibrin.

\begin{abstract}
Platelet concentrates are derivatives of blood that aid in haemostasis and wound healing after periodontal regenerative procedures. Its ability to act as a natural scaffold of growth factors has gained significance in many surgical procedures. This narrative review discusses the different platelet concentrates, their centrifugation protocols, advantages and disadvantages and their application in periodontal regenerative procedures. An electronic search of PubMed or MEDLINE was conducted for relevant material from the published literature up to 2020. The key words looked for were "Platelet concentrates, Platelet rich plasma, Platelet rich fibrin and periodontal regeneration." We have used the filters comparative human studies, animal studies, randomized controlled trials, case reports and systematic reviews. The searches were limited to articles in English language and articles describing platelet concentrates and its relation to periodontal regeneration were collected and used to prepare a concise review.
\end{abstract}

\section{INTRODUCTION}

Periodontitis is an inflammatory disease of the periodontium that leads to loss of tooth supporting tissues. Following periodontal therapy, healing occurs by regeneration, repair or a combination of both. The healing process depends on the availability of cell types needed and signalling cascades that regulate stimulation of these cells. The natural wound healing cascade is commenced by clot formation accompanied by proliferative and maturation phases. Thus, there is fibrin formation, platelet aggregation and release of several growth factors into tissues from platelets. Growth factors also aid in wound healing by favouring mitogenesis, chemotaxis, and angiogenesis [1,2].

${ }^{1}$ Department of Periodontics, Pushpagiri College of Dental Sciences, Perumthuruthy, Thiruvalla, Kerala, India.

*Correspondence: prabhakjohn@gmail.com
Platelets are small irregularly shaped cells present in blood that are derived from precursor megakaryocytes. They are approximately 2-3 $\mu \mathrm{m}$ in diameter, and constitute granules, few mitochondria, and prominent membrane structures. The canalicular system and a wellstacked tubular system on the cell surface helps in expulsion of growth factors upon platelet activation [3]. The substances located in the $\alpha$ granules, dense granules, and lysosomes of platelets modulate its activation. Of which, the most abundant ones are $\alpha$-granules that contains many bioactive mediators. During tissue injury, the platelets get activated and release wound healing factors like platelet derived growth factor (PDGF), vascular endothelial growth factor (VEGF), transforming growth factor (TGF) and epidermal growth factor (EGF) $[4,5]$. As the direct platelet influence subsides, macrophages arrive by means of vascular ingrowth stimulated by the platelets and assumes responsibility for wound-healing regulation by secreting their own factors. Thus, the platelets set the pace for wound repair [5].

As platelets contain biologically active proteins, they create a chemotactic gradient for recruitment 
of stem cells which undergoes differentiation and may promote healing by regeneration. Hence, autologous platelet concentrates have a promising scope in periodontal regeneration. In this review, we aimed to briefly describe the different platelet concentrates and their application in periodontal regenerative therapy.

\section{HISTORY OF PLATELET CONCENTRATES}

The first platelet product used as a surgical adjuvant was the "Fibrin glue" by Matras in 1970, that improved skin wound healing in rat models [6]. The regenerative potential of platelets was initially introduced in 1974 by Ross et al [7] and in 1986, Knighton et al [8], termed platelet concentrates as "plateletderived wound healing factors" as they promoted healing when used for skin ulcers. In 1998, Marx et al [9] introduced the first generation of platelet concentrates known as platelet rich plasma (PRP) and in 2000, Choukroun et al [10] introduced the "secondgeneration" of platelet concentrate known as platelet rich fibrin (PRF). Bielecki et al [11] and Cieslik-Bielecka et al $[12,13]$ defined PRP as an inactive substance and Platelet Rich Gel (PRG) as a biologically activated fibrin matrix in 2006. The concept of concentrated growth factors (CGF) was introduced by Sacco in 2006 which were found to be rich and dense fibrin blocks [14]. The first classification on platelet concentrates was proposed by Dohan Ehrenfest et al [15] in 2009 based on 2 key parameters that is, presence of cell content (mostly leukocytes) and the fibrin architecture. This classification included 4 main families of products: Pure platelet-rich plasma (P-PRP) or leukocyte-poor platelet rich plasma, Leukocyte and platelet-rich plasma (LPRP), Pure PRF (P-PRF) or leukocyte-poor PRF and Leukocyte and platelet-rich fibrin (L-PRF) (Figure 1). Subsequently Sohn introduced the concept of sticky bone in 2010 [16]. Recently, certain modifications of platelet rich fibrin were introduced. These were the advanced platelet rich fibrin (A-PRF) introduced by Choukroun in 2014 [17], Titanium prepared platelet rich fibrin (T-PRF) by Tunali et al [18] and injectable PRF (i-PRF) by Mourão et al in 2015 [19].

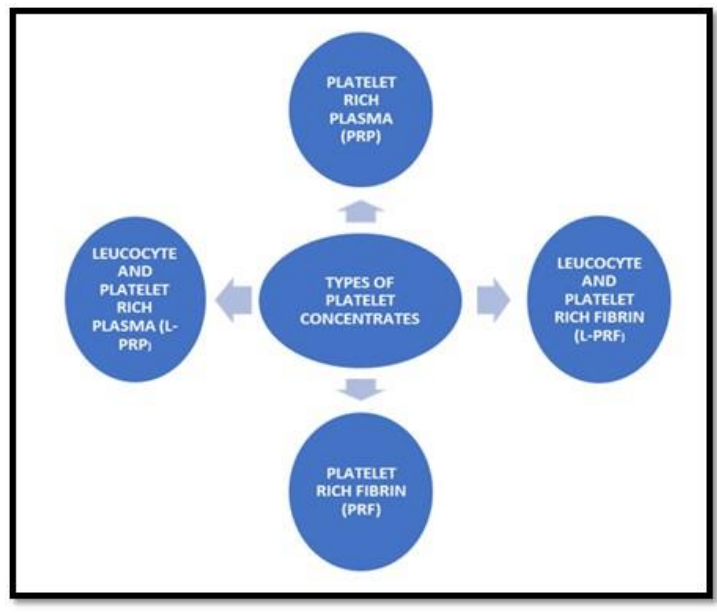

Figure 1: Types of Platelet Concentrates

$\begin{array}{llcr}\text { DIFFERENT } & \text { TYPES } & \text { OF } & \text { PLATELET } \\ \text { CONCENTRATES } & \text { AND } & \text { ITS } & \text { CLINICAL } \\ \text { APPLICATION } & & & \end{array}$

\section{PLATELET-RICH PLASMA (PRP)}

PRP mimics the terminal stage of coagulation cascade, that is fibrin clot formation. The release of growth factors through $\alpha$ granules increases early wound strength by cell proliferation and angiogenesis [20]. It also eliminates the risk of disease transmission due to its procurement from autologous blood.

Most commonly used method for preparation of PRP is Curasan method [21]. After drawing blood from a suitable patient, it undergoes a two-step centrifugation process. The first spin separates the RBC's from plasma after running for 10 mins at 2400 revolutions per minute (rpm). Then platelet poor plasma and the PRP with its "buffy coat" is transferred into a separate tube and then centrifugated for $15 \mathrm{~min}$ at $3600 \mathrm{rpm}$ (Figure 2). This gives pure PRP. The resultant product consists of 3 layers: A top layer of PPP; a middle layer, also called "buffy coat" of white blood cells and platelets; and a bottom layer of red blood cells. PRP is the middle layer. Then the PRP that is obtained is mixed with a sterile solution containing $10 \%$ calcium chloride and $100 \mathrm{U} / \mathrm{mL}$ of bovine thrombin and a gel is formed [21].

\section{Clinical applications}
a. Sinus Lift Procedures.
b. Ridge Augmentations.
c. Socket Preservation. 

d. Oro-nasal fistula repair.
e. Jaw reconstruction surgeries.
f. Intra Bony Defects.
g. Soft Tissue Procedures.

Various animal experiments, human clinical and randomized controlled trials, systematic reviews and meta-analysis have been conducted to analyse the efficacy of PRP in various periodontal regenerative procedures.

\section{Animal experiments}

Suaid et al conducted a histometric study in dogs and reported that when a combination of PRP with subepithelial connective tissue graft was used for treatment of gingival recessions, it was very effective in promoting formation of new cementum than when the graft was used alone [22].

Marcelo Diniz Carvalho et al reported that PRP failed to exert a significant effect on periodontal regeneration when combined with bovine glass for treatment of three walled intrabony defects in dogs [23].

\section{Clinical trials}

In a study conducted by Anitua, it was reported that there was an improvement in soft tissue repair and bone regeneration inside the extraction socket after applying PRP and that these sites could be used for implant placement in future [24].

Lekovic et al conducted a study in humans to compare a combination of bovine porous bone mineral, PRP, and guided tissue regeneration for management of intrabony defects. The study concluded that PRP had strong regenerative potential resulting in reduction of pocket depth and gain in clinical attachment level [25].

Wiltfang et al reported that PRP enhanced bony regeneration but did not affect the degradation of tricalcium phosphate material when betatricalcium phosphate was combined with PRP for sinus floor augmentation [26].

Riaz et al analysed the efficacy of PRP with hydroxyapatite crystals for maxillary sinus augmentation and reported that it was very effective in increasing the height of residual alveolar bone [27]. Dutta et al reported that autologous PRP was clinically biocompatible and showed improvement in soft tissue healing, bone regeneration and increased bone density in extraction sockets of mandibular third molar [28].

Srinivas et al reported that there was a significant improvement in clinical parameters when subepithelial connective tissue graft was used along with PRP to treat miller's class I and II gingival recession [29].

\section{Randomized controlled clinical trials}

A randomized controlled clinical trial reported that PRP improved the osteoconductive properties of anorganic bovine bone and increased bone regeneration in sinus floor augmentation [30].

Kutkut et al conducted a single-site, randomized controlled investigation to evaluate clinical and histologic outcome of using medical-grade calcium sulfate hemihydrate mixed with PRP for extraction socket preservation before implant placement. It was shown to regenerate greater percentage of new vital bone at 3 months with enhanced healing of bone [31].

In a randomized controlled clinical trial conducted by Eskan et al, PRP was found to enhance bone regeneration when combined with a cancellous allograft for ridge augmentation [32].

\section{Systematic review and meta-analysis}

Panda et al systematically evaluated the clinical and radiological outcomes of the additive efficacy of autologous platelet concentrates in treatment of intrabony defects when used alone and along with other regenerative procedures. PRP was found to be effective when used as an adjunct to grafting materials, but ineffective when used in combination with guided tissue regeneration procedures [33].

\section{Advantages:}

a. PRP enhances rapid regeneration by bringing cytokines and growth factors to the site.

b. It is free from concerns over transmissible disease.

c. Also, it is convenient and economical for patient.

\section{Disadvantages:}

a. Preparation protocol of PRP lacks standardization. 
b. Although never reported, the addition of bovine thrombin to the platelet concentrate could cause adverse reactions such as systemic lupus erythematosus.

These disadvantages have reduced the usage of PRP [34] and led to evolution of "second generation PRP" coined as Platelet rich fibrin which is purely an autologous human thrombin [20].

\section{PLATELET RICH FIBRIN (PRF)}

The PRF clot is obtained by the natural polymerization process during centrifugation. The fibrin architecture has a distinctive property of slow release of important growth factors such as transforming growth factor $\beta$, platelet-derived growth factor, vascular endothelial growth factor and matrix glycoproteins such as thrombospondin1 and cytokines for a period of about 28 days [35]. This enhances strong reparative and regenerative processes [36,37]. It also forms a trimolecular fibrin meshwork making it flexible to support cytokine function and cellular migration [34,37].

The ideal technique for PRF preparation was first put forward by Choukroun et al [10]. It involves collection of 5-ml of venous blood in two separate 6-ml tubes that are not coated with an anticoagulant and centrifuged at $3000 \mathrm{rpm}$ at 400 $\mathrm{g}$ for a period of $12 \mathrm{mins}$ (Figure 2) [10].

The end product consists of 3 layers: cellular PPP as the topmost layer, middle layer of PRF clot and bottom layer of red blood cells [37].

The main setback of this technique involves rapid coagulation of blood initiated on contact with the wall of the test tube. So, it is important to speed up the centrifugation process giving less working time for the clinician. It can also be moulded as a membrane by squeezing out fluids present in the fibrin clot $[38,39]$.

\section{Clinical applications}

a. Inclusion with Bone Grafts to accelerate the healing process.
b. Socket Preservation.
c. Root Coverage.
d. Intra Bony Defects and Furcation Defects.
e. As free Gingival Grafts for healing of palatal wound.

f. In sinus lift procedures.

Currently many studies have highlighted the regenerative potential of PRF when used in various periodontal surgical procedures and they are briefly described below.

\section{Animal studies}

Duan et al suggested that PRF combined with rat periodontal ligament stem cells provided a valuable tool for periodontal tissue engineering [40].

An animal study by Wang et al reported that the combined use of lyophilized PRF and osteogenic bone marrow mesenchymal stem cell sheet fragments enabled bone tissue regeneration. They suggested that the use of this combination may provide insights into the fabrication of engineered bone [41] .

\section{Clinical trials}

A study by Deepa and Jain (2015) has shown enhanced healing of gingival fenestrations after the use of PRF which suggested its use as a membrane in aesthetically demanding areas [42].

Al-Maawi et al studied on the interaction between 5 different collagen membranes like Mucograft, Bio-Gide, Mucoderm. Collprotect and BEGO with liquid PRF. It was concluded that it was possible to load these membranes with PRF which might help to enhance its bioactivity [43].

\section{Randomized controlled clinical trial}

Pradeep et al observed an improvement in clinical parameters when PRF was used in the regeneration of intra bony and furcation defects [44].

Agarwal et al evaluated the effect of PRF in combination with a decalcified freeze-dried bone allograft for treatment of intrabony defects and noted significant improvement in clinical and radiographic parameters after 12 months [45].

It was suggested the use of PRF in combination with demineralized freeze-dried bone allograft (DFDBA) for socket preservation as they observed a significantly lower gain in alveolar ridge dimensions with the use of DFDBA alone [46]. Another authors suggested that use of PRF membranes in multiple layers effectively increased the thickness of keratinized tissue when used for the treatment of Miller's Class I gingival recession [47]. 
Atchuta et al reported that a combination of PRF and DFDBA improved the clinical and radiographic parameters when used in regeneration of intrabony defects in chronic periodontitis patients [48].

\section{Systematic review and meta-analysis}

Based on their systematic review, Strauss et al concluded that the use of PRF would increase implant stability by reducing alveolar bone resorption and also would reduce postoperative pain and enhance wound healing after implant therapy [49].

A meta-analysis by $\mathrm{Li}$ et al proved that the synergistic application of PRF and $1 \%$ alendronate provided better results during periodontal bone regeneration [50].

Rodas et al reported in his systematic review and meta-analysis that PRF membranes are a promising alternative to autogenous gingival grafts in the treatment of Miller class I and II gingival recessions [51].

\section{Advantages of PRF over PRP:}

a. Ease of preparation and application,
b. Cost effective.
c. Reduced incidence of adverse reactions
due to absence of bovine thrombin or
anticoagulants.

\section{Disadvantages:}

a. The relatively low quantity of PRF obtained from samples.

b. PRF should be immediately used after preparation as it can lose the structural integrity by shrinkage due to dehydration [52].

\section{LEUCOCYTE PLATELET RICH FIBRIN (L-PRF)}

These are modified PRF clot or membrane that contains most of the platelets and leukocytes from the initial blood harvest plus platelet growth factors and stem cells entrapped within the fibrin network with enhanced strength [53]. It is obtained by modification of technique of pure platelet rich fibrin. Blood should be collected in less than 20 seconds in $9 \mathrm{ml}$ glass-coated plastic tubes. It is then immediately centrifuged at 2700 rpm for 12 minutes to produce L-PRF clots (Figure 2 ). The clots are then collected into a sterile surgical box and are compressed into membranes.
It could be used as a fibrin plug. It can also be used for sticky bone preparation by mixing with particulate bone.[54] A randomized controlled pilot clinical trial by Temmerman A et al has shown promising results when L-PRF membrane was used for increasing the width of keratinized mucosa around implants [55].

\section{ADVANCED PLATELET-RICH FIBRIN (A-PRF)}

A-PRF is another modified form of pure platelet rich fibrin obtained by decreasing the rpm and increasing the centrifugation time that is $1300 \mathrm{rpm}$ for 14 minutes (Figure 2). The resultant clot has an increased number of neutrophils and macrophages [53]. It is truly a revolutionary concept due to its ease of handling and the fact that it can be modified easily in a relatively short period of time. Also it provides the defect not only with a matrix that permits cell migration into the defected area but also provides important biological factors that accelerates wound-healing such as plateletderived growth factor (PDGF), transforming growth factor $\beta$ (TGF- $\beta$ ), platelet factor 4 (PF4), IL1 , vascular endothelial growth factor (VEGF), epidermal growth factor, endothelial cell growth factor (ECGF), platelet-derived endothelial growth factor (PDEGF), insulin-like growth factor, osteocalcin, osteonectin, fibrinogen, vitronectin, fibronectin, and thrombospondin [56]. Since it is a matrix that is obtained from patient's own blood, it eliminates the risk of foreign body reaction. It contributes to wound healing, tissue repair and can be used for tissue regeneration [57]. An invitro study revealed that both L-PRF and A-PRF stimulated the proliferation of periodontal ligament fibroblasts. A-PRF showed enhanced wound healing ability than L-PRF [58]. Positive results have been shown when A-PRF was used for treatment of gingival recessions $[59,60]$.

\section{INJECTABLE PLATELET-RICH FIBRIN (I-PRF)}

Injectable form of PRF is a platelet concentrate in liquid formulation which can be used alone or in combination with other biomaterials. It was observed to have a higher presence of regenerative cells and growth factors as compared to other forms of PRF. It also clots and attains a gel form after about 10-15 minutes for sustained release of growth factors in the tissue and induces expression of transforming growth factor- $\beta$ and collagen-1 mRNA [61].

I-PRF was produced by collecting blood in a $9 \mathrm{~mL}$ tube without anticoagulants and centrifuging it for 2 mins at $3300 \mathrm{rpm}$ (Figure 2). The resultant 
product obtained in the tube is an orange coloured fluid called I-PRF [19].

Recently a randomized controlled clinical trial observed that the application of i-PRF by a nonsurgical method influenced the increase in gingival thickness in individuals with thin periodontal phenotypes [62].

\section{TITANIUM PLATELET- RICH FIBRIN (T-PRF)}

T-PRF was introduced by Tunali et al in 2014, based on the hypothesis that titanium may be more efficient in activating platelets than silica used within glass tubes which were conventionally used for preparation of other platelet rich fibrin concentrates [18]. Although the use of L-PRF in regenerative procedures has been found to be successful, the use of glass tubes for blood collection has raised an issue of the possible health hazard due to the unavoidable silica contact as reported by $\mathrm{O}^{\prime}$ Connell. These silica particles were found to remain colloidally suspended in the 3 layers of the end product obtained after centrifugation thus posing a risk of these particles reaching the patient when used for treatment [63].

T-PRF is prepared by collecting $9 \mathrm{ml}$ blood drawn from the antecubital vein into Grade IV titanium tubes and immediately centrifuging at $2800 \mathrm{rpm}$ for 12 mins (Figure 2) [64]. The study conducted by Tunali et al found that the fibrin of T-PRF seemed to be more tightly woven and thicker than L-PRF [65]. As a result, it would remain in the tissue for a longer time [66].

Recently several randomized controlled clinical trials were conducted to evaluate the regenerative potential of T-PRF.

In a study by Chatterjee et al, use of T-PRF in the treatment of intra bony defects demonstrated significant improvements in periodontal parameters and radiographic findings [67].

An improvement in periodontal healing was observed when T-PRF membrane was combined with open flap debridement. This platelet concentrate also provided significantly higher concentrations of growth factors and lower RANKL/OPG ratio in GCF for about 4 to 6 weeks [68].

Another study that compared T-PRF and GTR when combined with open flap debridement showed significant improvement in clinical parameters compared with open flap debridement alone in treatment of intra bony defects with endo-perio lesions. The authors concluded that the use of TPRF may give similar successful results as GTR [69].

\section{CONCENTRATED GROWTH FACTORS PREPARATION (CGF)}

The preparation protocol used for CGF yields a much denser and larger fibrin matrix rich in growth factors. Intravenous blood samples are drawn from the patient into $10-\mathrm{ml}$ non-anticoagulant centrifuge tubes. It is then accelerated for $30 \mathrm{~s}$, centrifuged at $2700 \mathrm{rpm}$ for $4 \mathrm{~min}, 2400 \mathrm{rpm}$ for 4 $\mathrm{min}, 2700 \mathrm{rpm}$ for $4 \mathrm{~min}$, and $3000 \mathrm{rpm}$ for $3 \mathrm{~min}$, and then decelerated for $36 \mathrm{~s}$ to stop (Figure 2). Three layers are observed in the tube: a bottom layer red blood cells, a middle layer of fibrin gel with concentrated growth factor and platelet aggregation and a top layer of platelet-deprived plasma. First, the uppermost platelet-deprived fraction is removed with a sterile syringe. Then the layer containing concentrated growth factor is separated from the other two layers and pressed into a membrane [70].

It acts as a fibrin tissue adhesive thus acting as an effective haemostatic agent. It helps in wound healing and accelerates osteogenesis. It enhances attachment of a new connective tissue to the root surface thus improving wound stability. It also acts as a scaffold that helps in attachment of cytokines and cellular migration. CGF promotes epithelial, endothelial and epidermal regeneration and decreases dermal scarring. It possesses an antimicrobial as well as an anti-angiogenic property on chronic non healing wounds [71].

Clinical trials have shown that CGFs can act as an alternative to bone grafting and could be used for bone regeneration for sinus augmentation [72] and as a membrane support in implants to accelerate bone integration [73].

Results of a randomized clinical trial suggested that the use of CGF in combination with coronally advanced flap may increase the success of gingival recession treatment as there was an increase in keratinized gingival width and gingival thickness [74].

CGF when applied with bone graft materials could be used in treatment of bone defects which is based on significant radiographic defect bone fill. It also acts as an effective barrier to regenerate bone when associated with GBR and GTR procedures [75]. 


\section{AUTOLOGOUS FIBRIN GLUE (AFG) AND STICKY BONE}

The concept of mixing autologous fibrin glue with bone graft to obtain sticky bone was introduced by Sohn in the 2010 [76]. Autologous fibrin glue was obtained by centrifuging 20 - 60CC of blood in noncoated tubes at $2400-2700 \mathrm{rpm}$ for 2 mins to obtain two layers. The RBC's form the bottom layer and autologous fibrin glue forms the superficial layer. Then AFG was extracted using a syringe and mixed with particulate bone powder. It was allowed to rest for 5-10 mins for polymerization and this resulted in a yellow coloured mass called sticky bone [73]. It can used for space maintenance, angiogenesis and tension free primary suture in guided bone regeneration $[77,78]$.

It was found in a study that application of autologous fibrin glue after free gingival graft operation in the palatal donor region reduced post-operative complications and accelerated wound healing [79].

The use of "sticky bone" preparation was found to be useful for alveolar ridge augmentation as bone graft trapped within cross-linked fibrin meshwork prevented any undesirable movement of graft particles during the healing phase. This stabilized the bone graft onto the defect without the need of using any bone tacks or titanium mesh and this promoted tissue healing. The fibrin interconnection prevents ingrowth of soft tissue into the sticky bone graft [73].

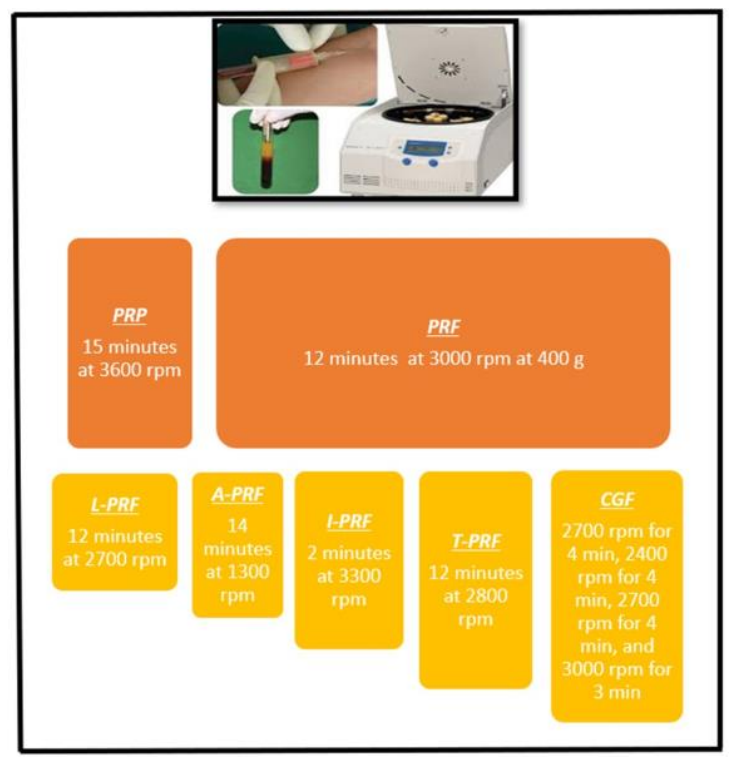

Figure 2: Centrifugation Protocol for Platelet Concentrates

\section{FUTURE PERSPECTIVES}

Platelets are being proposed to be used as carriers for loading drugs or biological therapies to specific target locations. Studies conducted on platelets have shown their capability of recognizing and interacting with tumour cells. So, development of new drug delivery systems and therapeutic strategies could be of use in management of tumours as this might help to minimize the side effects of chemotherapy such as cytotoxicity and non-specific targeting [80].

In a study that was conducted recently in a mouse model of lymphoma, doxorubicin loaded platelets enhanced intracellular accumulation of drugs in tumour cells through "tumour cell-induced platelet aggregation". This improved the anti-tumour activity of doxorubicin [81]. Zhen $\mathrm{Gu}$ and collaborators generated PD-1-expressing platelets to use it as post-surgery consolidation treatment in tumours. This could accumulate within the tumour surgical wound enhancing its anti-tumour immune response thus eliminating the residual tumour cells which could result in relapse of the tumour locally and distally [82].

One of the most abundant cell-derived microparticles are Platelet-derived microparticles (PMPs or platelet "dust") which are produced by platelets upon activation [83]. Various studies on these microparticles suggests its role as modulators of immune system as well as its role in various diseases [84]. PMPs also play a potential role in thrombosis and haemostasis, so a defect in the production of PMPs is associated with bleeding complications as seen in Scott syndrome patients $[85,86]$. These microparticles have gained attention as potential diagnostic markers when used for detection of rheumatoid arthritis and cardiovascular diseases $[87,88]$.

The use of advanced delivery systems such as liposomes for encapsulating the platelet concentrates has proved advantageous due to its biocompatibility, low immunogenicity, protection of growth factors against enzymatic degradation, and long-term bioavailability as well as ease of surface modification for selective targeted delivery. In vitro studies have shown favourable results for enhanced bone regeneration when biodegradable scaffolds such as calcium phosphates and poly lactic-co-glycolic acid were combined with biopolymers such as hyaluronic acid and gelatin for encapsulating PRP [89]. 


\section{CONCLUSION}

The use of platelet concentrates is a novel approach in the field of periodontal regenerative procedures. This is due to their ability to harbour growth factors that enables enhanced wound healing and accelerated regeneration of periodontal tissues. Being a natural and economical autologous product, it eliminates the risk of adverse reactions and disease transmission. Although various studies based on treatments using platelet concentrates have provided appropriate outcomes, further studies that includes large populations are still required to establish its efficacy.

\section{ACKNOWLEDGEMENT}

The authors would like to acknowledge the authors and publishers of all those articles and journals that has been cited in this manuscript.

\section{DECLARATION OF INTEREST}

The author reports no conflicts of interest. The author alone is responsible with the contents of the article.

\section{REFERENCES}

1. Kanakamedala A, Ari G, Sudhakar U, Vijayalakshmi R, Ramakrishnan T, Emmad P. Treatment of a furcation defect with a combination of platelet-rich fibrin (PRF) and bone graft-A case report. ENDO (LondEngl) 2009; 3:127-35.

2. Deodhar AK, Rana RE. Surgical physiology of wound healing: a review. J Postgrad Med 1997; 43:52-6.

3. Harrison P. Platelet function analysis. Blood Rev 2005; 19:111-23.

4. Marx, RE. Platelet-rich plasma: evidence to support its use. J Oral Maxillofac Surg 2004;62:489-496.

5. Marx RE. Platelet-rich plasma (PRP): what is PRP and what is not PRP? Implant Dent. 2001;10:225-8.

6. Matras H. [Effect of various fibrin preparations on reimplantation in the rat skin]. Osterr Z Stomatol 1970; 67: 338359.

7. Ross R, Glomset J, Kariya B, Harker L. A platelet dependent serum factor that stimulates the proliferation of arterial smooth muscle cells in vitro. Proc Natl Acad Sci USA 1974; 71:1207-10.

8. Knighton DR, Ciresi KF, Fiegel VD, Austin LL, Butler EL. Classification and treatment of chronic nonhealing wounds. Successful treatment with autologous platelet-derived wound healing factors (PDWHF). Ann Surg 1986; 204: 322330.

9. Marx RE, Carlson ER, Eichstaedt RM, Schimmele SR, Strauss JE, Georgeff KR. Platelet-rich plasma: Growth factor enhancement for bone grafts. Oral Surg Oral Med Oral Pathol Oral Radiol Endod 1998; 85: 638-646.

10. Choukroun J, Adda F, Schoeffler C, Vervelle A. An opportunity in perio-implantology: The PRF. Implantodontie 2001; 42:55-62.

11. Bielecki T, Gazdzik TS, Szczepanski T. Re: "The effects of local platelet rich plasma delivery on diabetic fracture healing". What do we use: Platelet-rich plasma or platelet-rich gel? Bone 2006; 39: 1388-1389.

12. Cieslik-Bielecka A, Gazdzik TS, Bielecki TM, Cieslik T. Why the platelet-rich gel has antimicrobial activity? Oral Surg Oral Med Oral Pathol Oral Radiol Endod 2007; 103: 303-305.

13. Cieslik-Bielecka A, Bielecki T, Gazdzik TS, Arendt J, Król W, Szczepanski T. Autologous platelets and leukocytes can improve healing of infected high-energy soft tissue injury. Transfus Apher Sci 2009; 41: 9-12.

14. Sacco L. Lecture, International academy of implant prosthesis and osteoconnection. Lecture 2006; 12: 4.

15. Dohan Ehrenfest DM, Del Corso M, Diss A, Mouhyi J, Charrier JB. Three-dimensional architecture and cell composition of a Choukroun's platelet-rich fibrin clot and membrane. J Periodontol 2010; 81: 546-555.

16. Sohn DS. Lecture titled with sinus and ridge augmentation with CGF and AFG, Symposium on CGF and AFG. Tokyo, June 6, 2010.

17. Choukroun J. Advanced PRF and i-PRF: Platelet concentrate or blood concentrate? J Periodontal Med Clin Pract 2014; $1: 3$.

18. Tunalı M, Özdemir H, Küçükodacı Z, Akman S, Fıratlı E. In vivo evaluation of titanium-prepared platelet-rich fibrin (TPRF): a new platelet concentrate. Br J Oral Maxillofac Surg 2013; 51: 438-443.

19. Mourão CF, Valiense H, Melo ER, Mourão NB, Maia MD. Obtention of injectable platelets rich-fibrin (i-PRF) and its polymerization with bone graft: technical note. Rev Col Bras Cir 2015; 42: 421-423.

20. Smith RG, Gassmann CJ, Campbell MS. Platelet-rich plasma: Properties and clinical applications. J Lanc Gen Hosp 2007; 2:73-7.

21. Weibrich G, Kleis WK, Hafner G, Hitzler WE, Wagner W. Comparison of platelet, leukocyte, and growth factor levels in point-of-care platelet-enriched plasma, prepared using a modified Curasan kit, with preparations received from a local blood bank. Clin Oral Implants Res 2003; 14:357-62.

22. Suaid FF, Carvalho MD, Santamaria MP, Casati MZ, Nociti FH Jr, Sallum AW, Sallum EA. Platelet-rich plasma and connective tissue grafts in the treatment of gingival recessions: a histometric study in dogs. J Periodontol. 2008;79:888-95. 
23. Carvalho MD, Suaid FF, Santamaria MP, et al. Platelet-rich plasma plus bioactive glass in the treatment of intra-bony defects: a study in dogs. J Appl Oral Sci. 2011;19:82-89.

24. Anitua E. Plasma rich in growth factors: Preliminary results of use in the preparation of future sites for implants. Int J Oral Maxillofac Implants 1999; 14:529-35.

25. Lekovic V, Camargo PM, Weinlaender M, Vasilic N, Kenney EB. Comparison of platelet-rich plasma, bovine porous bone mineral, and guided tissue regeneration versus platelet-rich plasma and bovine porous bone mineral in the treatment of intrabony defects: A re-entry study. J Periodontol 2002; 73:198-205.

26. Wiltfang J, Schlegel KA, Schultze-Mosgau S, et al. Sinus floor augmentation with beta-tricalciumphosphate: does platelet-rich plasma promote its osseous integration and degradation? Clin Oral Impl Res. 2003; 14:213-8.

27. Riaz R, Ravindran C, Ramkumar, Nandakumar. Efficacy of platelet rich plasma in sinus lift augmentation. J Maxillofac Oral Surg. 2010;9:225-230.

28. Dutta SR, Singh P, Passi D, Patter P. Mandibular third molar extraction wound healing with and without platelet rich plasma: a comparative prospective study. J Maxillofac Oral Surg. 2015; 14:808-15.

29. Srinivas BV, Rupa N, Halini Kumari KV, Prasad SS, Varalakshmi U, Sudhakar K. Root coverage using subepithelial connective tissue graft with platelet-rich plasma in the treatment of gingival recession: A clinical study. J Pharm Bioallied Sci. 2015;7(Suppl 2):S530-S538.

30. Torres J, Tamimi F, Martinez PP, et al. Effect of platelet-rich plasma on sinus lifting: a randomized-controlled clinical trial. J Clin Periodontol. 2009; 36:677-87.

31. Kutkut A, Andreana S, Kim HL, Monaco E Jr. Extraction socket preservation graft before implant placement with calcium sulfate hemihydrate and platelet-rich plasma: a clinical and histomorphometric study in humans. J Periodontol. 2012;83:401-9.

32. Eskan MA, Greenwell H, Hill M, et al. Platelet-rich plasma-assisted guided bone regeneration for ridge augmentation: a randomized, controlled clinical trial. J Periodontol. 2014; 85:661-8.

33. Panda S, Doraiswamy J, Malaiappan S, Varghese SS, Del Fabbro M. Additive effect of autologous platelet concentrates in treatment of intrabony defects: a systematic review and meta-analysis. J Investig Clin Dent. 2016; 7:13-26.

34. Shivashankar VY, Johns DA, Vidyanath S, Kumar MR. Platelet rich fibrin in the revitalization of tooth with necrotic pulp and open apex. J Conserv Dent 2012; 15:395-8.

35. Dohan Ehrenfest DM, de Peppo GM, Doglioli P, Sammartino G. Slow release of growth factors and thrombospondin1 in Choukroun's plateletrich fibrin (PRF): a gold standard to achieve for all surgical platelet concentrates technologies. Growth Factors 2009; 27: 63-69.

36. Dohan DM, Choukroun J, Diss A, Dohan SL, Dohan AJ, Mouhyi J, et al. Platelet-rich fibrin (PRF): A second-generation platelet concentrate. Part I: Technological concepts and evolution. Oral Surg Oral Med Oral Pathol Oral Radiol Endod 2006;101: e37-44.

37. Naik B, Karunakar P, Jayadev M, Marshal VR. Role of Platelet rich fibrin in wound healing: A critical review. J Conserv Dent 2013; 16:284-93.

38. Vivek G, Vivek KB, Singh GP, Ashish M, Rhythm B. Regenerative potential of platelet rich fibrin in dentistry: Literature review. Asian J Oral Health Allied Sci 2011; 1:22-8.

39. Sunitha Raja V, Munirathnam Naidu E. Platelet-rich fibrin: Evolution of a second-generation platelet concentrate. Indian J Dent Res 2008; 19:42-6.

40. Duan X, Lin Z, Lin X, et al. Study of platelet-rich fibrin combined with rat periodontal ligament stem cells in periodontal tissue regeneration. J Cell Mol Med. 2018;22:1047-1055.

41. Wang Z, Han L, Sun T, et al. Preparation and effect of lyophilized platelet-rich fibrin on the osteogenic potential of bone marrow mesenchymal stem cells in vitro and in vivo. Heliyon. 2019;5:e02739.

42. Deepa D, Jain N. Gingival fenestration defect in the maxillary anterior region treated with coronally positioned flap using platelet-rich fibrin membrane. J Interdiscipl Dent 2015; 5:140-4.

43. Al-Maawi S, Herrera-Vizcaíno C, Orlowska A, et al. Biologization of Collagen-Based Biomaterials Using LiquidPlatelet-Rich Fibrin: New Insights into Clinically Applicable Tissue Engineering. Materials (Basel). 2019;12:3993.

44. Pradeep AR, Rao NS, Agarwal E, Bajaj P, Kumari M, Naik SB. Comparative evaluation of autologous platelet-rich fibrin and platelet-rich plasma in the treatment of 3-wall intrabony defects in chronic periodontitis: A randomized controlled clinical trial. J Periodontol 2012; 83:1499-507.

45. Agarwal A, Gupta ND, Jain A. Platelet rich fibrin combined with decalcified freeze-dried bone allograft for the treatment of human intrabony periodontal defects: A randomized split mouth clinical trail. Acta Odontol Scand. 2016;74:36-43.

46. Thakkar DJ, Deshpande NC, Dave DH, Narayankar SD. A comparative evaluation of extraction socket preservation with demineralized freeze-dried bone allograft alone and along with platelet-rich fibrin: A clinical and radiographic study. Contemp Clin Dent 2016;7:371-6.

47. Culhaoglu R, Taner L, Guler B. Evaluation of the effect of dose-dependent platelet-rich fibrin membrane on treatment of gingival recession: a randomized, controlled clinical trial. J Appl Oral Sci. 2018;26:e20170278.

48. Atchuta A, Gooty JR, Guntakandla VR, Palakuru SK, Durvasula S, Palaparthy R. Clinical and radiographic evaluation of platelet-rich fibrin as an adjunct to bone grafting demineralized freeze-dried bone allograft in intrabony defects. J Indian Soc Periodontol. 2020;24:60-66. 
49. Strauss FJ, Stähli A, Gruber R. The use of platelet-rich fibrin to enhance the outcomes of implant therapy: A systematic review. Clin Oral Implants Res. 2018;29 Suppl 18(Suppl Suppl 18):6-19.

50. Li F, Jiang P, Pan J, Liu C, Zheng L. Synergistic Application of Platelet-Rich Fibrin and $1 \%$ Alendronate in Periodontal Bone Regeneration: A Meta-Analysis. Biomed Research International. 2019: 9148183.

51. Rodas MAR, Paula BL, Pazmiño VFC, Lot Vieira FFDS, Junior JFS, Silveira EMV. Platelet-Rich Fibrin in Coverage of Gingival Recession: A Systematic Review and Meta-Analysis. Eur J Dent. 2020;14:315-326.

52. Dohan DM, Del Corso M, Charrier J-B. Cyto-toxicity analyses of Choukroun's platelet-rich fibrin (PRF) on a wide range of human cells: The answer to a commercial controversy. Oral Surg Oral Med Oral Pathol Oral Radiol Endod 2007;103:587-3.

53. Dohan Ehrenfest DM, Pinto NR, Pereda A, Jiménez P, Corso MD, Kang BS, Nally M, Lanata N, Wang HL, Quirynen M. The impact of the centrifuge characteristics and centrifugation protocols on the cells, growth factors, and fibrin architecture of a leukocyte- and platelet-rich fibrin (L-PRF) clot and membrane. Platelets. 2018;29:171-184.

54. Corso M Del, Toffler M, Dohan Ehrenfest DM (2010) Use of an Autologous Leukocyte and Platelet-Rich Fibrin (L-PRF) Membrane in Post-avulsion Sites: An overview of Choukroun's PRF. J Implant Adv Clin Dent 2010;1: 27-35.

55. Temmerman A, Cleeren GJ, Castro AB, Teughels W, Quirynen M. L-PRF for increasing the width of keratinized mucosa around implants: A split-mouth, randomized, controlled pilot clinical trial. J Periodontal Res. 2018;53:793800.

56. Eppley BL, Pietrzak WS, Blanton M. Platelet-rich plasma: a review of biology and applications in plastic surgery. Plast Reconstr Surg. 2006; 118: 147e-159e.

57. Ghanaati S, Booms P, Orlowska A, Kubesch A, Lorenz J, Rutkowski J, Landes C, Sader R, Kirkpatrick C, Choukroun J. Advanced platelet-rich fibrin: A new concept for cell-based tissue engineering by means of inflammatory cells. J Oral Implantol 2014;40:679-689.

58. Pitzurra L, Jansen IDC, de Vries TJ, Hoogenkamp MA, Loos BG. Effects of L-PRF and A-PRF+ on periodontal fibroblasts in in vitro wound healing experiments. J Periodontal Res. 2020;55:287-295.

59. Sameera S, Nagasri M, Aravind Kumar P, Indeevar P, Raviraj K, Musalaiah SVVS. Comparison of two surgical techniques in the treatment of multiple gingival recessions sandwiched with a combination of A-PRF and L-PRF. Saudi Dent J. 2018;30:183-189.

60. Kumari, C. B. N., Ganesh, B., \& Vijayalakshmi, R. (2020). Advanced platelet rich fibrin in periosteal inversion technique for root coverage - A Case Report. Clinical Advances in Periodontics.

61. Miron RJ, Fujioka-Kobayashi M, Hernandez M, Kandalam U, Zhang Y, Ghanaati S, Choukroun J. Injectable platelet rich fibrin (i-PRF): opportunities in regenerative dentistry? Clin Oral Investig. 2017;21:2619-2627.

62. Ozsagir ZB, Saglam E, Sen Yilmaz B, Choukroun J, Tunali M. Injectable platelet-rich fibrin and microneedling for gingival augmentation in thin periodontal phenotype: A randomized controlled clinical trial. Journal of Clinical Periodontology. 2020;47:489-499.

63. O'Connell SM. Safety issues associated with platelet-rich fibrin method. Oral Surg Oral Med Oral Pathol Oral Radiol Endod. 2007;103:587-593.

64. Tunalı M, Özdemir H, Küçükodacı Z, et al. A novel platelet concentrate: titanium-prepared platelet-rich fibrin. Biomed Res Int. 2014;2014:209548.

65. Takemoto S, Yamamoto T, Tsuru K, Hayakawa S, Osaka A, Takashima S. Platelet adhesion on titanium oxide gels: effect of surface oxidation. Biomaterials. 2004;25:3485-3492.

66. Tunalı M, Özdemir H, Küçükodacı Z, Akman S, Fıratlı E. In vivo evaluation of titanium-prepared platelet-rich fibrin (TPRF): a new platelet concentrate. Br J Oral Maxillofac Surg. 2013;51:438-443.

67. Chatterjee, A.; Pradeep, A.R.; Garg, V.; Yajamanya, S.; Ali, M.M.; Priya, V.S. Treatment of periodontal intrabony defects using autologous platelet-rich fibrin and titanium platelet-rich fibrin: A randomized, clinical, comparative study. J. Investig. Clin. Dent. 2017, 8.

68. Arabaci T, Albayrak M. Titanium-prepared platelet-rich fibrin provides advantages on periodontal healing: A randomized split-mouth clinical study. J Periodontol. 2018 ;89:255-264.

69. Ustaoğlu G, Uğur Aydin Z, Özelçi F. Comparison of GTR, T-PRF and open-flap debridement in the treatment of intrabony defects with endo-perio lesions: a randomized controlled trial. Med Oral Patol Oral Cir Bucal. 2020;25:e117-e123.

70. Borsani E, Bonazza V, Buffoli B, Cocchi MA, Castrezzati S, et al. Biological Characterization and In Vitro Effects of Human Concentrated Growth Factor Preparation: An Innovative Approach to Tissue Regeneration. Biol Med (Aligarh). 2015;7: 256.

71. Nityasri, Aromal S, Pradeep KY, et al. Role of CGF (Concentrated Growth Factor) in periodontal regeneration. J Dent Health Oral Disord Ther. 2018;9:350-352.

72. Sohn DS, Heo JU, Kwak DH et al. Bone regeneration in the maxillary sinus using an autologous fibrin-rich block with concentrated growth factors alone. Implant Dent. 2011; 20:389-395.

73. Sohn DS, Huang B, Kim J, Park WE, Park CC. Utilization of autologous concentrated growth factors (CGF) enriched bone graft matrix (Sticky bone) and CGF-enriched fibrin membrane in Implant Dentistry. J. Implant Adv. Clin. Dent 2015;7:11-29.

74. Bozkurt Doğan Ş, Öngöz Dede F, Ballı U, Atalay EN, Durmuşlar MC. Concentrated growth factor in the treatment of adjacent multiple gingival recessions: a split-mouth randomized clinical trial. J Clin Periodontol. 2015;42:868-875. 
75. Gökmenoğlu C, Yavuz MC, Sadik E, Çanakçi V, Kara C. Treatment of Different Types of Bone Defects with Concentrated Growth Factor: Four Case Reports. Int J Oral Dent Health. 2016; 2:029(2):2.

76. Sohn DS. Lecture titled with sinus and ridge augmentation with CGF and AFG, Symposium on CGF and AFG. Tokyo, June 6, 2010.

77. Naag S, Savirmath A, Kalakonda BB, Uppada UK, Kamisetty S, Priyadarshini E. Platelet concentrates: Bioengineering dentistry's regenerative dreams. J Dent Res Rev 2015;2:86-90.

78. Agrawal AA. Evolution, current status and advances in application of platelet concentrate in periodontics and implantology. World J Clin Cases. 2017;5:159-171.

79. Mustafa Özay Uslu, Mehmet Kızıltoprak, Ömer Alperen Kırmızıgül. Autologous Fibrin Glue as a Novel Platelet Concentration in Palatal Wound Healing. Dent Res and Oral Health. 2019;2:40-46.

80. Wang S, Li Z, Xu R. Human Cancer and Platelet Interaction, a Potential Therapeutic Target. Int J Mol Sci. 2018;19:1246.

81. Xu P, Zuo H, Chen B, Wang R, Ahmed A, Hu Y, Ouyang J. Doxorubicin-loaded platelets as a smart drug delivery system: An improved therapy for lymphoma. Sci Rep. 2017;7:42632.

82. Zhang X, Wang J, Chen Z, Hu Q, Wang C, Yan J, Dotti G, Huang P, Gu Z. Engineering PD-1-Presenting Platelets for Cancer Immunotherapy. Nano Lett. 2018;18:5716-5725.

83. DovizioM, BrunoA, ContursiA, GrandeR, PatrignaniP. Platelets and extracellular vesicles in cancer: diagnostic and therapeutic implications. Cancer Metastasis Rev 2018;37:455-467.

84. Italiano JE Jr, Mairuhu AT, Flaumenhaft R. Clinical relevance of microparticles from platelets and megakaryocytes. Curr Opin Hematol. 2010;17:578-84.

85. Castaman G, Yu-Feng L, Rodeghiero F. A bleeding disorder characterised by isolated deficiency of platelet microvesicle generation. Lancet. 1996;347:700-1.

86. Weiss HJ. Scott syndrome: a disorder of platelet coagulant activity. Semin Hematol. 1994;31:312-9.

87. Boulanger CM, Amabile N, Tedgui A. Circulating microparticles: a potential prognostic marker for atherosclerotic vascular disease. Hypertension. 2006;48:180-6.

88. Knijff-Dutmer EA, Koerts J, Nieuwland R, Kalsbeek-Batenburg EM, van de Laar MA. Elevated levels of platelet microparticles are associated with disease activity in rheumatoid arthritis. Arthritis Rheum. 2002;46:1498-503.

89. Son SR, Sarkar SK, Nguyen-Thuy BL, Padalhin AR, Kim BR, Jung HI, Lee BT. Platelet-rich plasma encapsulation in hyaluronic acid/gelatin-BCP hydrogel for growth factor delivery in BCP sponge scaffold for bone regeneration. J Biomater Appl. 2015 ;29:988-1002.

\section{Editorial History}

Date of Submission: 12 September 2020

Review and Revision: 15 October 2020 to 13 November 2020

Accepted: 22 November 2020

Published: 01 December 2020

License Information: This work is licensed under a Creative Commons Attribution 